\title{
E-Bike Injuries: Experience from an Urban Emergency Department-A Retrospective Study from Switzerland
}

\author{
Sylvana Papoutsi, Luca Martinolli, Christian Tasso Braun, \\ and Aristomenis K. Exadaktylos \\ Department of Emergency Medicine, University Hospital and University of Bern, Freiburgstraße 16c, 3010 Bern, Switzerland \\ Correspondence should be addressed to Sylvana Papoutsi; dr.papoutsi@gmail.com
}

Received 23 November 2013; Revised 21 January 2014; Accepted 11 February 2014; Published 20 March 2014

Academic Editor: Chak W. Kam

Copyright (C) 2014 Sylvana Papoutsi et al. This is an open access article distributed under the Creative Commons Attribution License, which permits unrestricted use, distribution, and reproduction in any medium, provided the original work is properly cited.

Background. Between 2005 and 2012, annual sales of E-bikes in Switzerland increased from 1,792 to 52,941. This continuous and rapid transition from human-powered bicycles to an electric bicycle technology may indicate the increasing demand for low-cost transportation technology in combination with a healthy lifestyle. Material and Methods. In the present study, from April 2012 to September 2013, we retrospectively analysed E-bike accidents treated in the Emergency Department of our hospital by focusing on the following parameters: age, gender, time, period, and cause of the accident, as well as injury and outcome. Results. Patients were predominantly male. The mean age of injured E-cyclists was 47.5 years. The main causes of injury were self-accident. Most injuries were to the head/neck. The mean ISS was 8.48. The outcome showed that 9 patients were treated as outpatients, 9 were inpatients, and 5 patients were kept in the Intensive Care Unit (ICU). Only six patients underwent surgery (S). Discussion. This is the first attempt to evaluate E-bike injuries in Switzerland in an acute hospital setting. Since there is increasing popular preference for E-bikes as means of transportation and injuries to the head or neck are prevalent among E-cyclists, the hazard should not to be underestimated.

\section{Introduction}

Electric bikes or E-bikes are a category of modern vehicles that includes two-wheel bikes propelled by human pedalling, supplemented by electrical power from a storage battery (bicycle-style). The main technical components include a hub motor and lead-acid (VRLA) battery regulated by a controlled valve. Bicycle-style E-bikes typically have $36 \mathrm{~V}$ batteries and 180-250 W motors. E-bikes are regulated not to exceed $20 \mathrm{~km} / \mathrm{h}$ on electric power alone; however, many Ebikes can travel at speeds in excess of that limit and some are advertised as being able to reach $40 \mathrm{~km} / \mathrm{h}$ and more [1].

Approximately 29 million E-bikes were produced in 2010, representing a 24.7\% increase over 2009 [2]. By 2011, 120 million E-bikes had been registered in China [3], which might account for $90 \%$ of the global market [2]. Furthermore, a worldwide increase in demand is expected; it is estimated that 466 million E-bikes will have hit the road by 2016 [4].
These vehicles have also become a popular transportation mode for the Swiss [5], as they provide a long-term, less expensive, and convenient form of private mobility and are thus an attractive alternative to public transport, private cars, motorbikes, or normal cycling. Due to their low energy consumption and almost zero emissions [6], these vehicles are promoted by local governments [7]. They are safer than motorcycles, more comfortable and cheaper than the bus, and cheaper than the car. Longer distances can be travelled than with normal bikes [8]. Thus, from the user's perspective, Ebikes offer many advantages over regular bikes and walking.

As was mentioned before, E-bikes are gaining an increasing share of two-wheel transportation. Swiss statistics have shown that in 2005 there were a total of 1,792 E-bikes. The latest statistics from the Swiss Institute for Bicycles (SFZ) indicate that E-bike sales in Switzerland have "sky rocketed," with 52,941 annual E-bike sales and an annual rate of increase of $15.2 \%$ (Table 1) [5]. 
TABLE 1: Overview of Switzerland's bicycle market [5].

\begin{tabular}{cccc}
\hline Year & Total bike sales & E-bike sales & Proportion \% \\
\hline 2005 & 280,840 & 1,792 & $+0.6 \%$ \\
2006 & 299,286 & 3,181 & $+1.1 \%$ \\
2007 & 314,161 & 5,825 & $+1.9 \%$ \\
2008 & 314,784 & 11,631 & $+3.7 \%$ \\
2009 & 349,903 & 23,886 & $+6.8 \%$ \\
2010 & 351,003 & 39,247 & $+11.2 \%$ \\
2011 & 351,808 & 49,615 & $+14.1 \%$ \\
2012 & 348,643 & 52,941 & $+15.2 \%$ \\
\hline
\end{tabular}

Notwithstanding the huge increase in the number of Ecyclists, the literature on E-bikes injuries is relatively limited. We have now performed the first retrospective study of E-bike injuries at a European level I trauma centre.

\section{Material and Methods}

Our University Department of Emergency Medicine, the only Level I centre in the canton of Bern, serves about 1,8 million people and treats more than 35,000 cases per year, caring for patients older than 16 years. Our retrospective 18month observational study, from April 2012 to September 2013 , comprised adult patients ( $\geq 16$ years old) admitted to our Emergency Department (ED) in relation to an accident that had occurred with an E-bike. All patients presenting to the ED with an E-bike accident during the study period were included in our study. Patients were identified using the appropriate search string in the patient demographic field of our computerised patient database. Since this medical database allows instantaneous recall of past diagnostic reports, consultations, X-rays, and other relevant medical documents, the authors retrospectively analysed the E-bike injured patients, including gender, age $(<40$ or $\geq 40$ years old), time (morning 05:01 am-13:30 pm, afternoon 13:31 pm17:30 pm, evening 17:31 pm-21:00 pm, and night 21:01 pm05:00 am), season (spring, summer, autumn, and winter), and cause of accident: being caught in a tram rail (occurred after being caught in a tram rail), vehicle collision (occurred after collision with a vehicle), and self-accident (occurred due to alcohol intoxication, due to high speed, or without a known reason), as well as severity of injury, medical diagnosis, and, finally, the outcome (treated as home/outpatient, kept in hospital, or as inpatient, kept in the Intensive Care Unit and mortality). Each diagnosis was classified according to the Abbreviated Injury Scale (AIS) handbook 2008 [9] and the Injury Severity Score (ISS) was calculated for each patient [10].

\section{Results}

During the 18-month study period, from April 2012 until September 2013, a total of twenty-three $(n=23)$ E-bike accidents were reported to our ED. Seventy percent $(n=16)$ of the injured were male and $30 \%(n=7)$ female. A total of $18(78.3 \%)$ of the injured E-cyclists were above the age of 40 .
The median age was 47.5 years. The detailed characteristics of each patient are shown in Table 2.

Additionally, $43.5 \%(n=10)$ of accidents took place during the morning, $26.1 \%(n=6)$ during the afternoon, $17.4 \%(n=4)$ during the evening, and only $13.0 \%(n=3)$ during the night. The most common season was summer, with $39.1 \%(n=9)$ of accidents, followed by spring and autumn, each with $26.1 \%(n=6)$, as well as winter with $8.7 \%$ $(n=2)$. Approximately $60.9 \%(n=14)$ of injured E-cyclists were involved in a self-accident of known/unknown cause: these were related to a high speed $(n=4 ; 17.4 \%)$, to alcohol intoxication $(n=2 ; 8.7 \%)$, or no known reason $(n=8$; $34.8 \%)$. Furthermore, 5 (21.7\%) E-cyclists were injured after being caught in a tram rail and $4(17.4 \%)$ due to a collision with a vehicle.

The head/neck was the most common body region injured $(27.4 \%)$. Injuries to the upper extremities $(22.6 \%)$ and face $(19.3 \%)$ were almost as common. Injuries to the chest (11.3\%), abdomen (9.7\%), lower extremities (6.4\%), and external skin (3.2\%) were less frequent (Figure 1). The types and locations of the injuries are summarised in Table 3. In particular, the most common injuries to the head/neck were mild brain injury (14.9\%) and subarachnoid haemorrhage (7.4\%); to the face, contused lacerated wounds $(10.4 \%)$ and fractures $(4.5 \%)$; to the upper extremities, clavicle fractures (11.9\%) and contusive trauma (8.9\%); to the chest, rib fractures (6.0\%); to the low extremities, contusive trauma (4.5\%); to the abdomen, contusive trauma $(3.0 \%)$; to the external skin, (4.5\%) slight excoriation (without contusive trauma). The most frequent types of injuries were fractures (32.6\%)especially fractures to the clavicle (38.1\%) - contusive trauma (20.9\%), and mild brain injuries (14.9\%) (Figure 2).

The ISS scores were between 2 and 29, with an average value of 8.48 . Of the $14(60.8 \%)$ hospitalised patients, only 6 (42.8\%) underwent surgery.

Only 9 patients (39.1\%) were sent home or for outpatient treatment, but 14 patients $(60.81 \%)$ were treated in hospital. In the latter group, 9 patients $(39.1 \%)$ were treated in general wards (3 patients in the Oral/Maxillofacial Unit, 3 in the Neurosurgery Unit, 2 in the Orthopaedics/Traumatology Unit, and 1 in the Dermatology Unit) and the remaining 5 patients (21.7\%) were kept in ICU. No E-cyclist died.

\section{Discussion}

The current retrospective 18-month descriptive study aims to make a preliminary evaluation of E-bike injuries, in the Emergency Department (ED) of an acute Level I Trauma Centre in Switzerland. To the best of our knowledge, this is one of the first studies that systematically analyses the accidents related to this means of transport at a European hospital.

Our results showed that E-bike users are predominantly male; this finding is in full concordance with the current international literature [11-15]. Among accident victims, $78.3 \%$ are $\geq 40$ years old, with a median age of 47.5 . Our finding with regard to the median age is in good agreement with a recent report (SINUS-Report 2013) from The Swiss 
TABLE 2: E-cyclists' characteristics.

\begin{tabular}{|c|c|c|c|c|c|c|c|c|}
\hline $\begin{array}{l}\text { Patients } \\
(n)\end{array}$ & Sex & Age & Time & Period & Cause of accident & Region of injury & ISS & Outcome \\
\hline 1 & $\mathrm{M}$ & 38 & Evening & Summer & Being caught in a tram rail & Head/neck, face, upper extremities, external & 6 & Home \\
\hline , & M & 63 & Night & Spring & Self-accident (alcohol intoxication) & Head/neck, face, upper extremities, abdomen & 12 & Hospital \\
\hline 3 & $\mathrm{~F}$ & 41 & Evening & Spring & Self-accident (unknown reason) & Upper extremities, chest, abdomen, external & 3 & Home \\
\hline 4 & M & 51 & Afternoon & Summer & Being caught in a tram rail & Head/neck, face, upper extremities & 3 & Home \\
\hline 5 & M & 54 & Afternoon & Spring & Self-accident (unknown reason) & Head/neck, face, chest & 17 & Hospital \\
\hline 6 & M & 45 & Afternoon & Spring & Collision with vehicle & Face, upper extremities, chest, lower extremities & 6 & Hospital \\
\hline 7 & $\mathrm{~F}$ & 27 & Afternoon & Summer & Self-accident (high speed) & Head/neck, face, upper extremities, abdomen & 6 & Hospital/S* \\
\hline 8 & $\mathrm{~F}$ & 41 & Morning & Autumn & Self-accident (high speed) & Lower extremities & 4 & Home \\
\hline 9 & $\mathrm{~F}$ & 57 & Afternoon & & Self-accident (unknown reason) & Head/neck, face, upper extremities & 9 & Hospital \\
\hline 10 & $\mathrm{~F}$ & 43 & Morning & Autumn & Self-accident (unknown reason) & Head/neck, chest & 10 & $\mathrm{ICU}^{* *}$ \\
\hline 11 & M & 42 & Morning & Summer & Collision with vehicle & Upper extremities, chest, lower extremities & 3 & Home \\
\hline 12 & M & 76 & Afternoon & Autumn & Collision with vehicle & Head/neck, chest, upper extremities, abdomen & 29 & $\mathrm{ICU} / \mathrm{S}$ \\
\hline 13 & M & 59 & Night & Autumn & Self-accident (unknown reason) & Head/neck, face & 17 & $\mathrm{ICU} / \mathrm{S}$ \\
\hline 14 & M & 48 & Morning & Autumn & Being caught in a tram rail & Face, chest & 5 & Home \\
\hline 15 & $\mathrm{~F}$ & 64 & Morning & Winter & Self-accident (unknown reason) & Head/neck, face & 4 & Hospital \\
\hline 16 & $\mathrm{~F}$ & 35 & Morning & Winter & Self-accident (unknown reason) & Head/neck, face, upper extremities & 6 & Hospital/S \\
\hline 17 & M & 62 & Morning & Spring & Collision with vehicle & Upper extremities, lower extremities & 13 & Hospital/S \\
\hline 18 & M & 40 & Evening & Spring & Self-accident (high speed) & Head/neck, face, upper extremities & 5 & Home \\
\hline 19 & M & 61 & Morning & Summer & Self-accident (high speed) & Head/neck & 9 & ICU \\
\hline 20 & M & 21 & Morning & Summer & Self-accident (unknown reason) & Head/neck & 1 & Home \\
\hline 21 & M & 41 & Morning & Summer & Being caught in a tram rail & Head/neck, upper extremities, abdomen & 6 & Hospital/S \\
\hline 22 & M & 46 & Evening & Summer & Being caught in a tram rail & Head/neck, upper extremities & 8 & Home \\
\hline 23 & M & 37 & Night & Summer & Self-accident (alcohol intoxication) & Head/neck, abdomen & 13 & ICU \\
\hline
\end{tabular}

${ }^{*}$ Surgery; ${ }^{* *}$ Intensive Care Unit.

TABLE 3: Number and type of injuries for each body region.

\begin{tabular}{|c|c|c|c|c|}
\hline Head/Neck & $\mathrm{MBI}^{*} n=10(14.9 \%)$ & $\mathrm{SAH}^{* *} n=5(7.4 \%)$ & Fractures $n=4(6.0 \%)$ & $\mathrm{CLW}^{* * *} n=3(4.5 \%)$ \\
\hline Face & CLW $n=7(10.4 \%)$ & Fractures $n=3(4.5 \%)$ & Contusive trauma $n=1(1.5 \%)$ & Teeth fracture $n=1(1.5 \%)$ \\
\hline Upper extremities & \multicolumn{2}{|c|}{ Clavicle fractures $n=8(11.9 \%)$} & \multicolumn{2}{|c|}{ Contusive trauma $n=6(8.9 \%)$} \\
\hline Chest & \multicolumn{2}{|c|}{ Rib fracture $n=4(6.0 \%)$} & Contusive trauma $n=2(3.0 \%)$ & Pneumothorax $n=1(1.5 \%)$ \\
\hline Abdomen & \multicolumn{2}{|c|}{ Contusive trauma $n=2(3.0 \%)$} & \multicolumn{2}{|c|}{ Free intra-abdominal fluid $n=1(1.5 \%)$} \\
\hline Lower extremities & Fractures $n=2(3.0 \%)$ & Contusive & auma $n=3(4.5 \%)$ & CLW $n=1(1.5 \%)$ \\
\hline External skin & \multicolumn{4}{|c|}{ Excoriation $n=3(4.5 \%)$} \\
\hline
\end{tabular}

Council for Accident Prevention [16]. Du et al., in a Chinese study of 323 E-bike injuries, reported an average age of 43.8 years [15]. However, some of their patients were children. More and more elderly adults in Switzerland choose E-bikes for transportation, perhaps because this takes less time and is less exhausting than riding a conventional bike. In Australia, another study reported that using an E-bike rather than a conventional bike increased the likelihood of preferring an active method of transport, and was significantly quicker, with less perceived effort [17].

The present study also showed that most E-bike accidents occurred during the morning, followed by evening and afternoon, as well as in the summer months. Du et al. also analysed the time of the day and concluded that most accidents occurred during the night (18:00 pm-23:59 pm). Our findings are consistent with peak travel to and from work; they may indicate the use of E-bikes as a means of transportation to and from work.

Furthermore, we noticed that most E-bike injuries were caused by self-accident and a significant percentage of accidents were attributed to being caught in a tram rail. It is worth mentioning that we analysed the tram rails as a cause of accident as these were very frequent among our patients. In the study of Du et al., it was reported that $48.6 \%$ of injuries involved collisions with motor vehicles. In contrast, we found that only $17.4 \%$ of accidents were caused by collision with vehicles. This may be related to the traffic density in the two countries. 


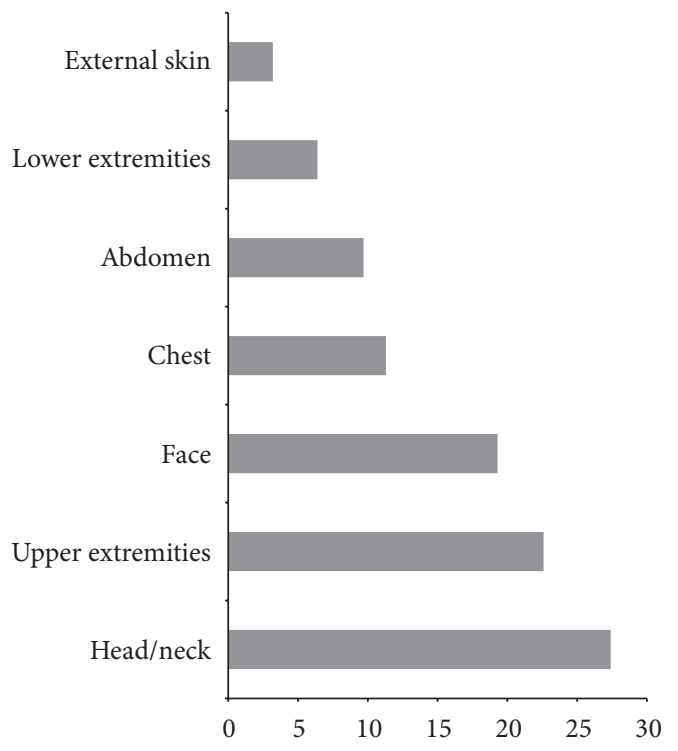

Figure 1: Percentage of injured regions among E-cyclists (\%).

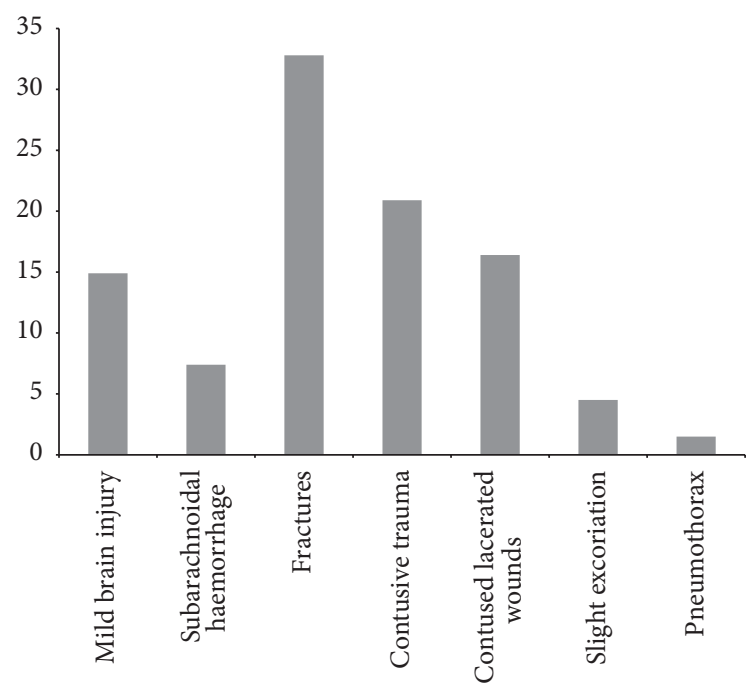

FIgURE 2: Type of injuries in E-cyclists in percentage (\%).

Another Chinese study found that E-bike related casualties had increased in recent years, notwithstanding the decreases in the total number of road traffic collisions and deaths [18]. In Switzerland, the proportion of E-bikes in cycling traffic is rising steadily. In 2010 , only $1.5 \%$ of cyclists rode E-bikes, with increases to $2.3 \%$ in 2011 and 3.8\% in 2012 (Swiss Council for Accident Prevention). Unfortunately, no detailed data for E-bike injuries are available for Switzerland for these years.

The injuries to the head/neck region included a high proportion of mild brain injury. In the whole body, the most common injuries were fractures and contusions, followed by contused lacerated wounds and superficial excoriations (Figure 2). Du et al. made similar findings with respect to the head/neck region; however, the most common injuries they found were fractures of the limbs, whereas in our study, they were clavicle fractures. Moreover, the second most commonly injured body region in our study was the upper extremities (Figure 1). This is in contrast to Du et al., who recorded $46.4 \%$ of injuries in the head/neck and $20.7 \%$ in the trunk. These may relate to the failure of more E-cyclists to wear helmets in China. Indeed, the rate of helmet wearing among Swiss E-cyclists is currently $75.0 \%$ (Swiss Council for the Accident Prevention) in Switzerland [16] and only 9.0\% in China [15]. Considering that the impacts and hazards are likely to be similar in the two countries, the evidence and the effectiveness of helmets in reducing bicyclist [19] and motorcyclist [20] head injuries clearly support helmet use for E-cyclists.

It is remarkable that we found no hospital mortality and our ISS score was relatively low. Unfortunately, no ISS scores on E-bike injuries have been published in comparable studies. Only eight E-bike deaths were reported in 2012 (Swiss Federal Roads Authority), which was six more than in the previous year [16]. However, Du et al. failed to find any hospital fatality in the course of their 6-month study in China. In another study carried out in Hangzhou, with its population of circa 7,800,000, Feng et al. recorded 397 E-bike related deaths between 2004 and 2008 [18].

In their retrospective study on motorcycle and bicycle accidents, Wagner et al. concluded that these accidents cause major injuries in older patients with more severe ISS. They concluded that fewer older bicyclists used helmets and that they suffered more sustained or severe head injuries, with greater functional decline [21]. An Australian study to evaluate the factors influencing the outcome of 208 motorcycle crash victims showed that losing control due to intoxication, collision with another vehicle, or travelling above the speed limit was associated with the worst patient outcome; travelling in excess of $50 \mathrm{kph}$ increased the risk of intracranial injury [22]. Our patient group was too small to allow similar conclusions.

Limitations. Our findings have to be considered with some caution, as the study was conducted retrospectively. As the information in our medical history database is presented in a narrative comment, there is no guarantee that the number of E-cyclists was fully reported. Furthermore, our study was limited to adults ( $\geq 16$ years old), as children are treated at a separate Emergency Department in our hospital. Since the weather conditions during each accident were not reported, as a first approximation, we analysed our data by season. It has been demonstrated that helmets protect riders of two-wheel vehicles and so correlate negatively with admission to an ICU $[23,24]$. Unfortunately, our register data did not document helmet use.

\section{Conclusions}

E-bikes are a new mode of transport; prices are coming down and purchases will probably continue to rise. Injuries to the head and neck are common. Further studies are needed to compare accidents suffered by E-cyclists with those suffered by bicyclists and motor cyclists. 


\section{Conflict of Interests}

The authors declare that there is no conflict of interests regarding the publication of this paper.

\section{References}

[1] J. Weinert, C. Ma, and C. Cherry, "The transition to electric bikes in China: history and key reasons for rapid growth," Transportation, vol. 34, no. 3, pp. 301-318, 2007.

[2] Research in China, "Industry report of electric bicycles in China, 2010-2011," Tech. Rep., 2011.

[3] L. Yao and C. Wu, "Traffic safety of e-bike riders in China: safety attitudes, risk perception and aberrant riding behaviors," Transportation Research Record. Journal of the Transportation Research Board \& Transportation Research Board, vol. 2314, pp. 49-56, 2013.

[4] D. Hurst and C. Wheelock, Electric Two-Wheel Vehicles (Electric Bicycles, Mopeds, Scooters and Motorcycles): Market Analysis and Forecasts, Boulder Pike Research, Boulder, Colo, USA, 2010.

[5] Statistiken über den Velomarkt Schweiz. Velosuisse, http:// www.velosuisse.ch/de/statistik_aktuell.html.

[6] “The electric bicycle race. MPR," July/August 2010.

[7] Mit E-Bike-Pilotstation die Nachfrage überprüfen, http://www .bernerzeitung.ch/region/thun/Mit-EBikePilotstation-die-Nachfrage-ueberpruefen/story/18104412.

[8] C. Cherry and R. Cervero, "Use characteristics and mode choice behavior of electric bike users in China," Transport Policy, vol. 14, no. 3, pp. 247-257, 2007.

[9] T. A. Gennarelli and E. Wodzin, "Abbreviated Injury Scale update 2008," Association for the Advancement of Automotive Medicine, vol. 1, no. 1, 2008.

[10] “Injury severity score 2012," http://www.trauma.org/archive/ scores/iss.html.

[11] W. Du, J. Yang, B. Powis et al., "Understanding on-road practices of electric bike riders: an observational study in a developed city of China," Accident Analysis and Prevention, vol. 59, pp. 319-326, 2013.

[12] Y. Zhang and C. Wu, "The effects of sunshields on red light running behaviour of cyclists and electric bike riders," Accident Analysis and Prevention, vol. 52, pp. 210-218, 2013.

[13] C. Wu, L. Yao, and K. Zhang, "The red-light running behavior of electric bike riders and cyclists at urban intersections in China: an observational study," Accident Analysis and Prevention, vol. 49, pp. 186-192, 2012.

[14] L. Yao and C. Wu, "Traffic safety of E-Bike riders in China: safety attitudes, risk perception, and aberrant riding behaviours," in Proceedings of the Annual Meeting of the Transportation Research Board (TRB '11), November 2011.

[15] W. Du, J. Yang, B. Powis et al., "Epidemiological profile of hospitalised injuries among electric bicycle riders admitted to a rural hospital in Suzhou: a cross-sectional study," Injury Prevention, vol. 20, pp. 128-133, 2014.

[16] "Unfälle mit E-Bikes häufig selbstverschuldet," http://www .news.ch/Unfaelle+mit+E+Bikes+haeufig+selbstverschuldet/ 603601/detail.htm.

[17] M. Ralfe and J. Williams, "Comparing electric bicycle and conventional bicycle use-implications for increasing daily activity," Journal of Science and Medicine in Sport, vol. 10, no. 1, 2008.

[18] Z. Feng, R. P. Raghuwanshi, Z. Xu, D. Huang, C. Zhang, and T. Jin, "Electric-bicycle-related injury: a rising traffic injury burden in china," Injury Prevention, vol. 16, no. 6, pp. 417-419, 2010.

[19] D. C. Thompson, F. P. Rivara, and R. Thompson, "Helmets for preventing head and facial injuries in bicyclists," Cochrane Database of Systematic Reviews, no. 2, Article ID CD001855, 2000.

[20] B. C. Liu, R. Ivers, R. Norton, S. Boufous, S. Blows, and S. K. Lo, "Helmets for preventing injury in motorcycle riders," Cochrane Database of Systematic Reviews, no. 1, Article ID CD004333, 2008.

[21] J. Wagner, A. Rai, F. Ituarte, A. Tillou, H. Cryer, and J. R. Hiatt, "Two-wheel vehicular trauma: an age-based analysis," The American Surgeon, vol. 78, no. 10, pp. 1066-1070, 2012.

[22] G. Cunningham, D. Chenik, and R. Zellweger, "Factors influencing motorcycle crash victim outcomes: a prospective study," ANZ Journal of Surgery, vol. 82, pp. 551-554, 2012.

[23] A. Philip, W. Fangman, J. Liao, M. Lilienthal, and K. Choi, "Helmets prevent motorcycle injuries with significant economic benefits," Traffic Injury Prevention, vol. 14, pp. 496-500, 2013.

[24] L. Ganti, A. Bodhit, Y. Daneshvar et al., "Impact of helmet use in traumatic brain injuries associated with recreational vehicles," Advances in Preventive Medicine, vol. 2013, Article ID 450195, 6 pages, 2013. 


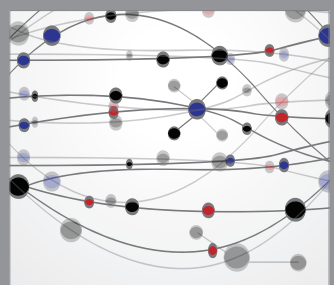

The Scientific World Journal
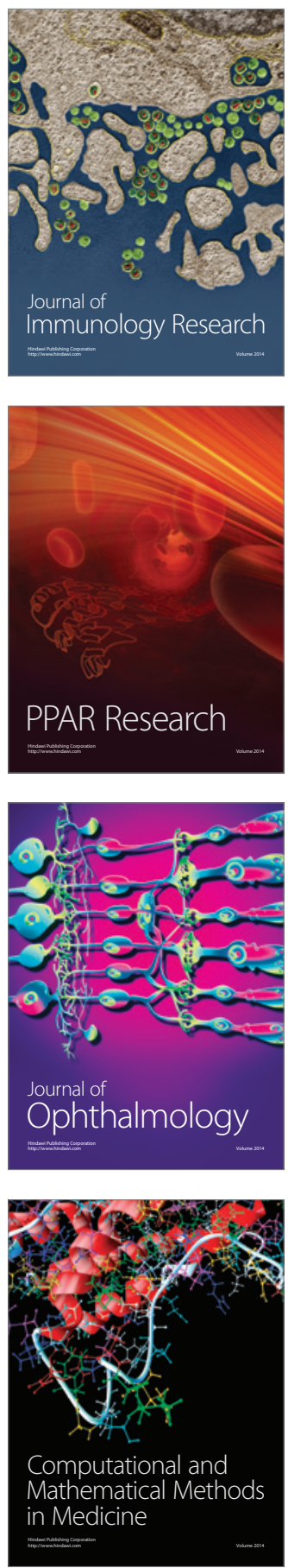

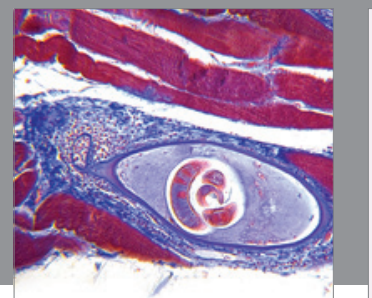

Gastroenterology

Research and Practice
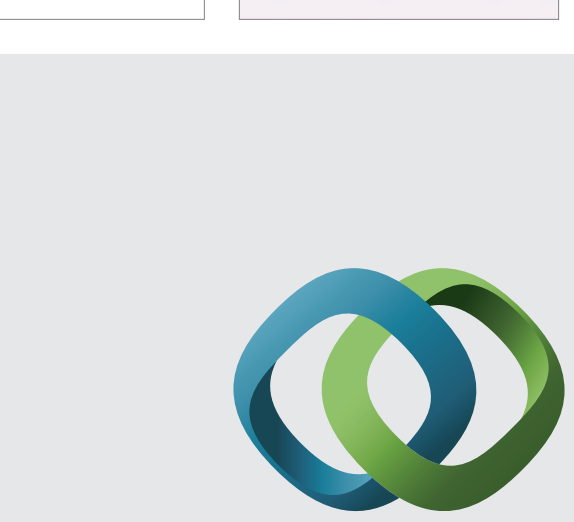

\section{Hindawi}

Submit your manuscripts at

http://www.hindawi.com
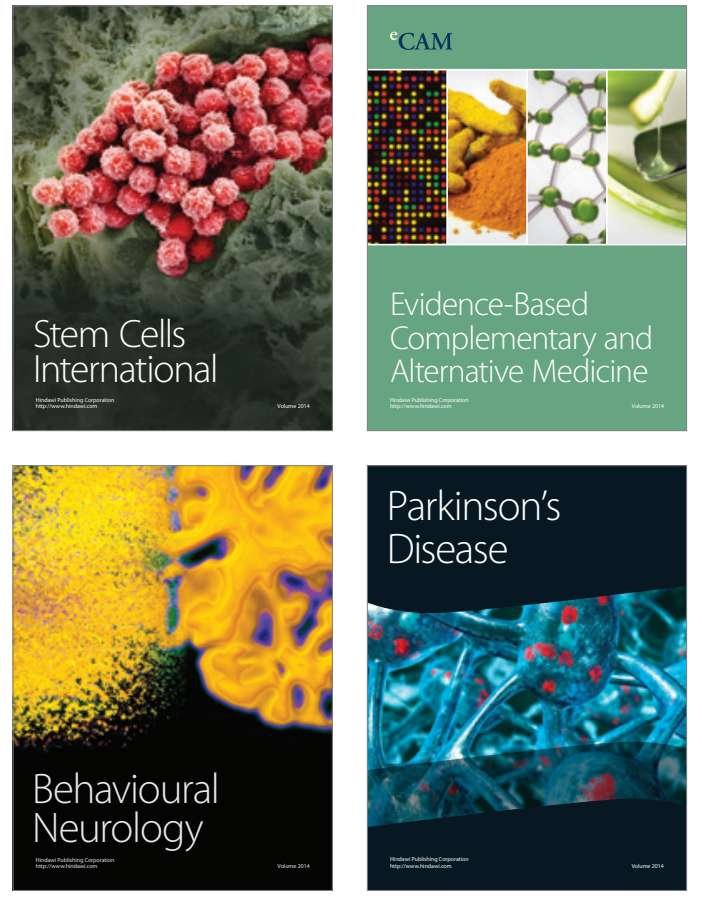
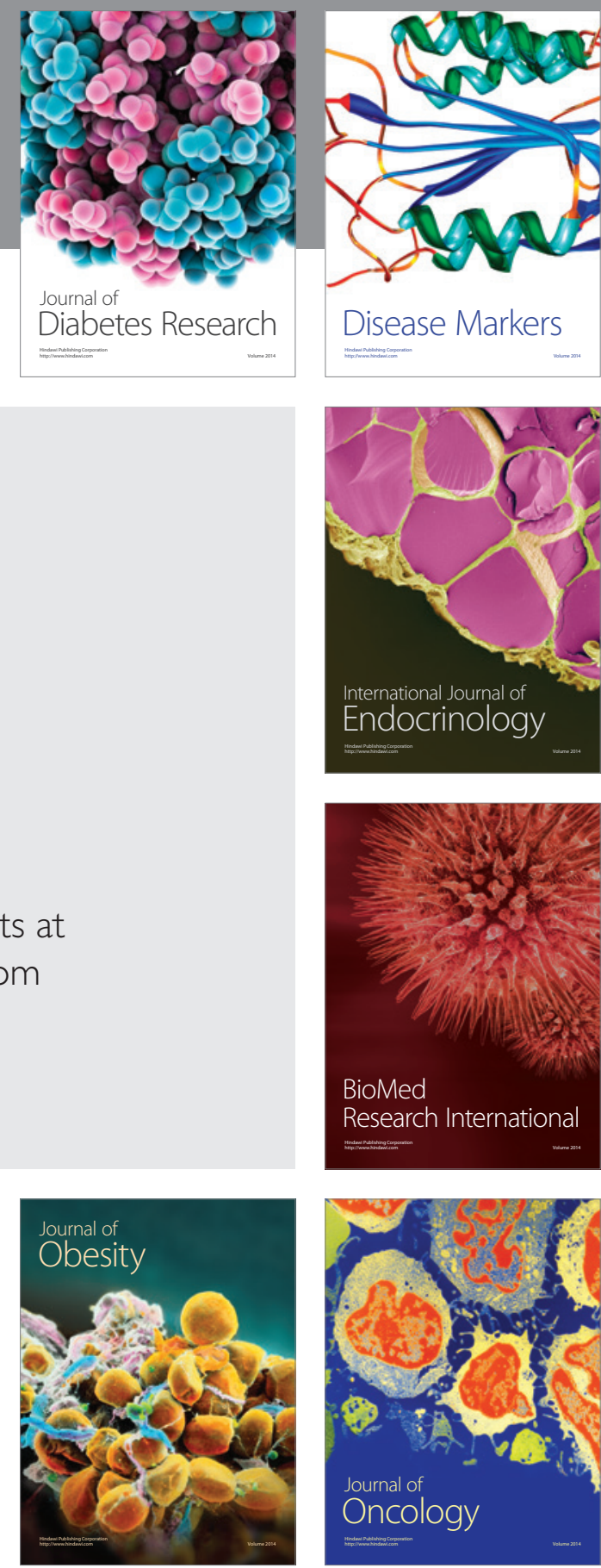

Disease Markers
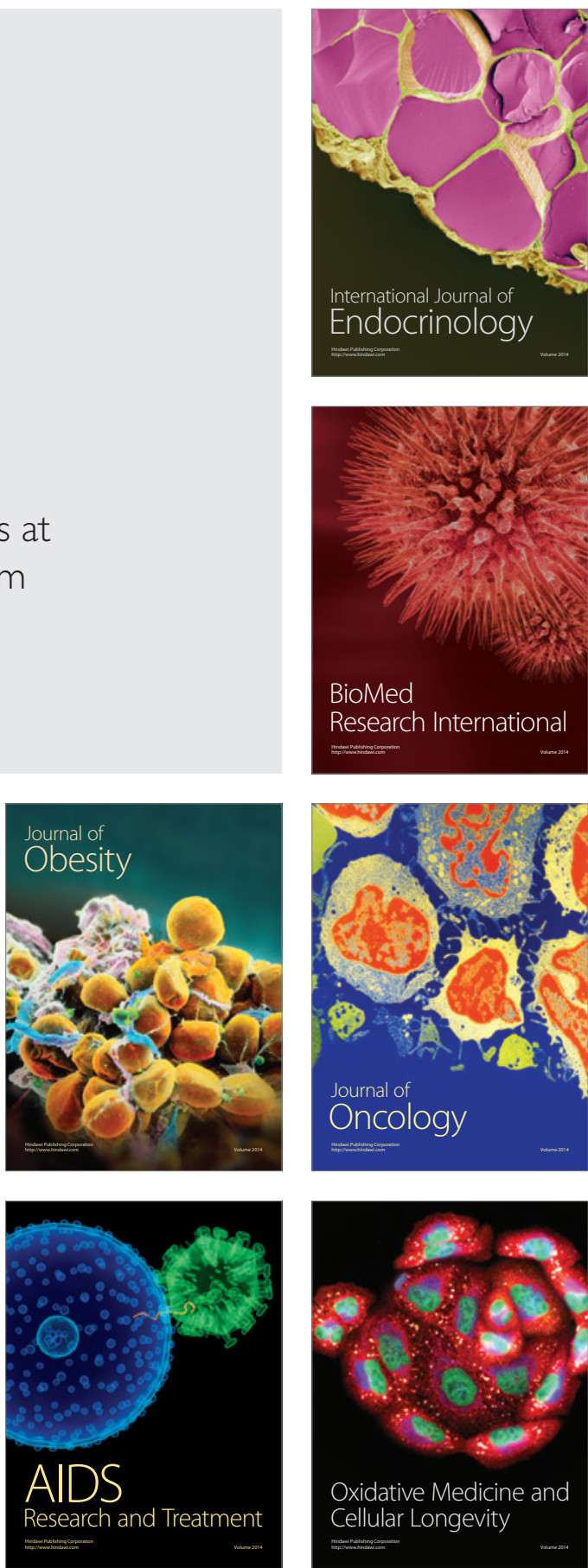